\title{
Microstructure and luminescence dynamics of ZnCdO films with high Cd content deposited on different substrates by DC magnetron sputtering method
}

I. Shtepliuka, Volodymyr Khranovskyy, G. Lashkarev, V. Khomyak, A. Ievtushenko, V. Tkach, V. Lazorenko, I. Timofeeva and Rositsa Yakimova

\author{
Linköping University Post Print
}

\section{Tweet}

N.B.: When citing this work, cite the original article.

Original Publication:

I. Shtepliuka, Volodymyr Khranovskyy, G. Lashkarev, V. Khomyak, A. Ievtushenko, V. Tkach, V. Lazorenko, I. Timofeeva and Rositsa Yakimova, Microstructure and luminescence dynamics of $\mathrm{ZnCdO}$ films with high Cd content deposited on different substrates by DC magnetron sputtering method, 2013, Applied Surface Science.

http://dx.doi.org/10.1016/j.apsusc.2013.03.132

Copyright: Elsevier

http://www.elsevier.com/

Postprint available at: Linköping University Electronic Press http://urn.kb.se/resolve?urn=urn:nbn:se:liu:diva-90907 


\title{
Microstructure and luminescence dynamics of $\mathrm{ZnCdO}$ films with high $\mathrm{Cd}$
} content deposited on different substrates by DC magnetron sputtering

\section{method}

\author{
I. Shtepliuk ${ }^{1}$, V. Khranovskyy ${ }^{2}$, G. Lashkarev ${ }^{1}$, V. Khomyak ${ }^{3}$, A. Ievtushenko ${ }^{1}$, \\ V. Tkach $^{4}$, V. Lazorenko ${ }^{1}$, I. Timofeeva ${ }^{1}$, and R. Yakimova ${ }^{2}$ \\ ${ }^{1}$ Institute for Problems of Material Science, National Academy of Sciences of Ukraine, Kiev \\ 03680,Ukraine \\ ${ }^{2}$ Linköping University, Department of Physics, Chemistry and Biology, Linköping 58381, Sweden \\ ${ }^{3}$ Chernivtsi National University, Chernivtsi 58012, Ukraine \\ ${ }^{4}$ Bakul Institute for Superhard Materials, National Academy of Sciences of Ukraine, Kiev 04074, \\ Ukraine
}

\begin{abstract}
Investigation of $\mathrm{Cd}$ behaviour in the $\mathrm{ZnCdO}$ alloys, where $\mathrm{Cd}$ content exceeds the solubility limit, is of importance due to possible impurity segregation and second phases' formation in this material. We have studied the $\mathrm{Cd}$ behaviour in the $\mathrm{Zn}_{1-\mathrm{x}} \mathrm{Cd}_{\mathrm{x}} \mathrm{O}$ films deposited by dc magnetron sputtering on different substrates: c-plane $\mathrm{Al}_{2} \mathrm{O}_{3}$, bare $\mathrm{Si}(100)$ and $\mathrm{Au}(45 \mathrm{~nm}) / \mathrm{Si}(100)$. It is revealed that $\mathrm{Cd}$ content of 10 at. $\%$ in the target results in average $6-8$ at. $\%$ of $\mathrm{Cd}$ in the films, depending on the substrate type. Structural analysis based on x-ray diffraction revealed the absence of Cd-related secondary phases. Time-resolved photoluminescence (TRPL) and high-resolution energy dispersive X-ray analysis (EDX) help to understand the recombination dynamics of spontaneous emission and to establish correlations between cadmium content and radiative lifetime. We have revealed that the internal quantum efficiency is influenced by the $\mathrm{Cd}$ content and defect concentration. It is suggested that increasing of the cadmium content results in the reduction of nonradiative recombination centers originating from point defects.
\end{abstract}

Key words: ZnCdO, growth kinetics, lattice defects, photoluminescence, substrate 


\section{Introduction}

$\mathrm{ZnO}$ has been recognized as a material of paramount importance for fabricating optoelectronic devices operating in the blue/UV region [1 - 10]. This is due to a combination of its specific semiconductor and material properties. It has a wide direct band gap of $3.36 \mathrm{eV}$ at room temperature, which can be modified in a wide range via alloying with $\mathrm{Cd}$ (down to $2.8 \mathrm{eV}$ ) or $\mathrm{Mg}$ (up to $4.0 \mathrm{eV}$ ) [2]. The exciton binding energy is around $60 \mathrm{meV}$ at room temperature, which is one of the highest among other optoelectronic materials. It should be noted that the band-gap engineering for $\mathrm{ZnO}$ is vital for its further progress in optoelectronics: isoelectronic cadmium impurity is an ideal candidate for reducing the band gap of zinc oxide [3]. $\mathrm{ZnCdO}$ solid solution has the advantage of tunability of the alloy band gap, allowing larger control over the spectrum of emitted light from near UV to visible [4, 5]. Many interesting phenomena like tunable electroluminescence from $\mathrm{n}-\mathrm{ZnCdO} / \mathrm{p}-\mathrm{GaN}$ heterojunction [6], luminescence enhancement effect of deuterium in $\mathrm{ZnO} / \mathrm{ZnCdO}$ quantum wells [7], enhancement of the spontaneous emission rate from $\mathrm{ZnCdO}$ quantum wells by surface plasmon coupling [8], rectifying behavior of a $\mathrm{p}-\mathrm{n}$ junction based on $\mathrm{n}-\mathrm{Zn}_{0.94} \mathrm{Cd}_{0.06} \mathrm{O} / \mathrm{p}$-SiC heterostructures [9] and effect of transparent thin film transistor based on $\mathrm{ZnCdO}[10]$ have already been reported. However, many fundamental optical properties of $\mathrm{ZnCdO}$ have not been extensively studied. The dynamic behavior of the carriers in the $\mathrm{ZnCdO}$ solid solutions is not yet fully understood and is still controversial. Yamamoto et. al [11] reported that the PL lifetime of $\mathrm{ZnO}(125 \mathrm{ps})$ gradually increases with increasing Cd content under 0.19, showing a typical slow PL lifetime of 125 ps. At Cd content over 0.3 , it drastically increased up to $54 \mathrm{~ns}$ and was two orders longer than that in $\mathrm{ZnO}$ [11]. The decay times $\tau_{1}$ and $\tau_{2}$ for the excitons at $8 \mathrm{~K}$ were 16 and $80 \mathrm{ps}$, respectively, in $\mathrm{Zn}_{0.85} \mathrm{Cd}_{0.15} \mathrm{O}$ grown by remote-plasma enhanced metalorganic chemical vapor deposition [12]. However, the exciton at $2 \mathrm{~K}$ has the radiative lifetime of $3 \mathrm{~ns}$ in the $\mathrm{Zn}_{0.843} \mathrm{Cd}_{0.157} \mathrm{O}$ grown by molecular-beam epitaxy [13]. This large discrepancy of lifetimes is closely related to the crystalline quality and the photoluminescence center is very sensitive to the micro-structure. Therefore, this useful information of TRPL dependency on the crystalline quality can be extended into the optimization of the growth conditions of the $\mathrm{ZnCdO}$ 
solid solution. Thus, it is important to understand the fundamental properties of the optical process and emission mechanism in $\mathrm{ZnCdO}$ alloys depending on $\mathrm{Cd}$ content and growth parameters (for example, a substrate type), especially for $\mathrm{Cd}$-rich $\mathrm{ZnCdO}$ alloys for further improvement of optoelectronic devices.

Earlier, $\mathrm{ZnCdO}$ films grown on different substrates, such as indium tin oxide (ITO) [14], sapphire [15], Si [16], quartz [17] and glass [18] have already been studied. For example, Ma et. al [19] have shown that the type of substrate significantly influences the structure, morphology and the transmittance of the $\mathrm{Zn}_{1-\mathrm{x}} \mathrm{Cd}_{\mathrm{x}} \mathrm{O}$ films. It was demonstrated that the $\mathrm{Zn}_{0.8} \mathrm{Cd}_{0.2} \mathrm{O} / \mathrm{a}-\mathrm{Al}_{2} \mathrm{O}_{3}$ film had a better crystal quality than that on the Si substrate. Additionally, there was a difference of the band gap energies between the samples which were deposited on the glass and $a$-sapphire substrates. It was explained that the ions coalesce more tightly in the $\mathrm{Zn}_{0.8} \mathrm{Cd}_{0.2} \mathrm{O} / \mathrm{a}-\mathrm{Al}_{2} \mathrm{O}_{3}$ film and the evaluated band-gap-energy was larger. Moreover, Fouzri et al. [15] have revealed that the substrate orientation significantly influences the $\mathrm{Cd}$ incorporation in $\mathrm{ZnCdO}$. Nevertheless, the substrate effect on the structural and optical features of $\mathrm{ZnCdO}$ films is not fully understood, and requires further investigations. Clear understanding of the substrate effect is valuable for potential applications of $\mathrm{ZnCdO}$ ternary alloy and respective device fabrication since the kind of the growth surface determines the device performance.

In this work, we report structural and luminescence properties of $\mathrm{ZnCdO}$ films produced by direct current (DC) magnetron sputtering on different substrates: bare and Au-coated (30 nm) Si (100) and $\mathrm{c}-\mathrm{Al}_{2} \mathrm{O}_{3}$ (0001). Assuming that the solubility limits may be influenced by the tensile strain in the films, we have chosen the substrates that provide in-plane tensile strain for $\mathrm{ZnCdO}$ growth. We also present results of the time-resolved photoluminescence (TR PL) measurement of the $\mathrm{ZnCdO}$ layers at room temperature. Our experimental data strongly support the hypothesis that the substrate type may considerably influence the PL dynamics, equilibrium cadmium content and microstructure of the $\mathrm{ZnCdO}$ ternary alloys.

\section{Experimental details}


The films of $\mathrm{Zn}_{1-\mathrm{x}} \mathrm{Cd}_{\mathrm{x}} \mathrm{O}$ ternary alloy were deposited on $\mathrm{Au} / \mathrm{Si}$ (100), Si (100) and c- $\mathrm{Al}_{2} \mathrm{O}_{3}(0001)$ substrates at the temperature of $400{ }^{\circ} \mathrm{C}$ by direct current magnetron sputtering. A disc of zinccadmium alloy (100 $\mathrm{mm}$ in a diameter) with a purity of $99.99 \%$ was used as a target. High purity argon and oxygen gases were used as the sputtering and the reactive gas, respectively. The targetto-substrate distance was $40 \mathrm{~mm}$. The chamber was pumped to a base pressure of $1 \cdot 10^{-4} \mathrm{~Pa}$ before deposition. The films were grown in the ambient with $\mathrm{Ar} / \mathrm{O}_{2}$ ratio of $4: 1$. The dc power was maintained at $150 \mathrm{~W}$. The deposition time was $60 \mathrm{~min}$ for all samples. The crystal structure of the samples was studied by the XRD analysis where the $\mathrm{CuK} \alpha_{1}$ radiation was used as a source $(\lambda=$ $0.154056 \mathrm{~nm})$. The XRD measurements were carried out by the DRON-4 Powder Diffraction system; a scan rate of $1 \% \mathrm{~min}$ and a step size of $0.01^{\circ}$ were used. It is important to note that the analysed surface is about $\sim 1 \mathrm{~cm}^{2}$ and the penetration depth of $\mathrm{X}$-rays at $20-40 \mathrm{keV}$ is a few microns. Measurement error of the peak position is about $\pm 0.01^{\circ}(2 \theta)$. Error of the c-lattice parameter is about $\pm 0.0003 \mathrm{~nm}$. The relative error in the FWHM has been estimated to be $\pm 2 \%$. Time-resolved PL (TR PL) measurements were performed by means of a third harmonic of a femtosecond pulsed Ti:sapphire laser mode-locked laser with a repetition frequency of $75 \mathrm{MHz}$ set at $266 \mathrm{~nm}$ as an excitation source. The resulting PL was recorded by a streak camera system with a time resolution of $\sim 8 \mathrm{ps}$. Scanning electron microscopy (SEM) was used to reveal the uniformity of the films (ZEISS EVO $50 \mathrm{XVP}$ ). An acceleration voltage was fixed at $20 \mathrm{kV}$. An elemental analysis of the ZnCdO films were also done by ZEISS EVO 50 XVP SEM using energy dispersive X-ray spectroscopy (EDX) furnished INCA 450 (OXFORD Instruments). The atomic concentrations of $\mathrm{Zn}, \mathrm{Cd}$ and $\mathrm{O}$ elements were determined within the relative experimental error of $\sim 2 \%$. An operating voltage for EDX analysis was set to $20 \mathrm{kV}$. The area of $500 \mu \mathrm{m}$ x $500 \mu \mathrm{m}$ was studied to determine the concentrations of the elements. The thickness of the films was $\sim 1.5 \mu \mathrm{m}$ for all samples, determined from the SEM images of the cross section of the films (not shown in the paper).

\section{Results and discussions}


In the case of heteroepitaxial growth, substrate influences the structural parameters of the overgrown material due to lattice and thermal expansion coefficient (TEC) mismatch [20, 21]. Table 1 represents the structural parameters of the $\mathrm{ZnO}$ in comparison to silicon and sapphire substrates.

Table 1 .

The properties of $\mathrm{ZnO}$, Si and $\mathrm{Al}_{2} \mathrm{O}_{3}$

\begin{tabular}{|c|c|c|c|}
\hline Parameter & $\mathbf{Z n O}$ & $\mathbf{S i}$ & $\mathbf{A l}_{\mathbf{2}} \mathbf{O}_{\mathbf{3}}$ \\
\hline $\mathrm{E}_{\mathrm{g}}(\mathrm{eV})$ & $3.34^{\mathrm{a}}$ & $1.12^{\mathrm{d}}$ & $8.8^{\mathrm{e}}$ \\
\hline Lattice constant $(\AA)$ & $\begin{array}{c}\mathrm{a}=3.250^{\mathrm{b}} \\
\mathrm{c}=5.205^{\mathrm{b}}\end{array}$ & $\mathrm{a}=5.43^{\mathrm{f}}$ & $\begin{array}{c}\mathrm{a}=4.758^{\mathrm{h}} \\
\mathrm{c}=12.992^{\mathrm{h}}\end{array}$ \\
\hline $\begin{array}{c}\text { Coefficient of Thermal } \\
\text { expansion }\left(10^{-6} \mathrm{~K}\right)\end{array}$ & $2.9^{\mathrm{c}}$ & $2.6^{\mathrm{f}}$ & $7.5^{\mathrm{c}}$ \\
\hline
\end{tabular}

${ }^{a}$ Ref.[1]. ${ }^{b}$ Ref.[10]. ${ }^{c}$ Ref.[22]. ${ }^{\text {d }}$ Ref.[23]. ${ }^{\mathrm{f}}$ Ref.[24]. ${ }^{\mathrm{e}}$ Ref.[25]. ${ }^{\mathrm{h}}$ Ref.[26].

Fig. 1 illustrates the $\theta-2 \theta$ XRD patterns of $\mathrm{Zn}_{1-\mathrm{x}} \mathrm{Cd}_{\mathrm{x}} \mathrm{O}$ films grown on different substrates, confirming that the $\mathrm{Zn}_{1-\mathrm{x}} \mathrm{Cd}_{\mathrm{x}} \mathrm{O}$ ternary alloys possess a hexagonal wurtzite structure. All deposited films have a polycrystalline structure with strong (002) preferred orientation. The relative intensity of the (002) diffraction peak provides further evidence that the films are preferentially oriented in the c-axis direction.
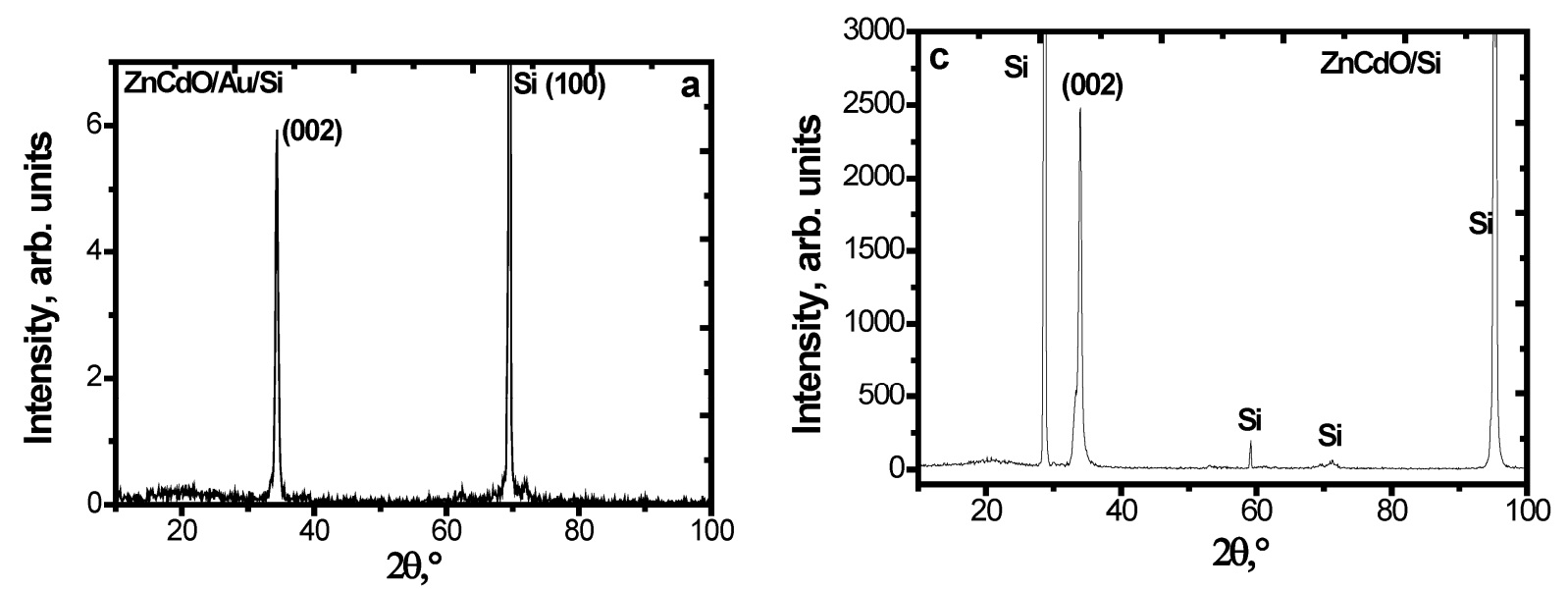


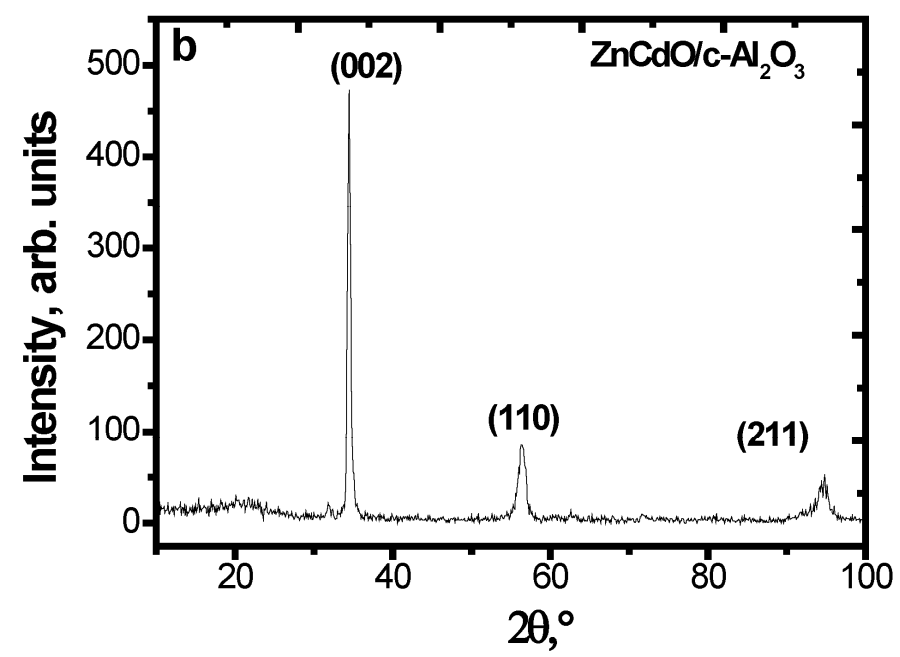

Fig. 1 XRD patterns of $\mathrm{Zn}_{1-x} \mathrm{Cd} d_{x} \mathrm{O}$ films grown on (a) Au-coated $\mathrm{Si}$, (b) Si and (c) $c-\mathrm{Al}_{2} \mathrm{O}_{3}$ substrates.

The growth of the $\mathrm{ZnO}$ film along the (002) direction is due to the lowest surface free energy of the (002) plane of $\mathrm{ZnO}$ [27]. The XRD $\theta-2 \theta$ scan of $\mathrm{ZnCdO}$ films, grown on Au coated Si substrate, revealed only peak due to the reflections from (002) plane of $\mathrm{ZnO}$ (Fig. 1a). Only $\mathrm{ZnO}$ wurtzite phase, therefore, is detected and no evidence of other phases was observed. Similarly, the film on a bare Si substrate displayed only the (002) reflection peak (Fig. 1b).

In both cases the substrate peaks are also visible, thereby indicating a rather small thickness of the films. While the $\mathrm{ZnCdO}$ films, grown on sapphire, are characterized by the additional weak peaks of (110) and (211), as shown in Figure 1c. Such a feature may be explained in terms of the high lattice mismatch between (0001) sapphire and (0001) $\mathrm{ZnO}$ (Table 1), which can promote the lattice disorder, reorientation of the crystallites and appearance of the new diffraction peaks. In order to confirm this assumption we have calculated the Lotgering factor [28] for different samples and have found that the sample grown on the sapphire exhibit Lotgering factor of $\sim 0.75$. Whereas the samples grown on the $\mathrm{Si}$ and $\mathrm{Au}$-coated $\mathrm{Si}$ demonstrate the higher degree of orientation of the $\mathrm{ZnCdO}$ films along the c-axis (Lotgering factor $\sim 1$ ). It should be noted that no reflexes corresponding to the separate $\mathrm{CdO}$ phase or metallic $\mathrm{Cd}$ clusters are observed. It may be caused by two factors: (i) XRD method is not sensitive enough and possible formation of the second phases could not be observed and (ii) in the case of non-equilibrium growth conditions, the level of $\mathrm{Cd}$ 
incorporation may exceed the $\mathrm{Cd}$ solubility limit in $\mathrm{ZnO}$, which was theoretically suggested $2 \%$ by the Brown et. al. [29]. We assume that in our case we have a fluctuation of Cd content and possible segregation of the dopant on the grain boundaries, film/substrate interface etc. Nevertheless, part of $\mathrm{Cd}$ ions incorporates into $\mathrm{ZnO}$ lattice. In order to investigate this assumption, we performed a comparative analysis of XRD (002) peaks appertaining to $\mathrm{Zn}_{1-\mathrm{x}} \mathrm{Cd}_{\mathrm{x}} \mathrm{O}$ films grown on the different substrates. A vertical line (Fig. 2) in this figure corresponds to the standard (002) reflex of $\mathrm{ZnO}$ wurtzite structure accordingly to JCPDS card 36-1451 [30]. Here we have to be aware that in our case several different factors may effect on the (002) peak position: i) substrate lattice mismatch ii) TEC mismatch between substrate and film iii) Cd incorporation. Interestingly, these factors are commonly interrelated and complementary. A certain type of the substrate, depending on the provided in-plane strain - tensile or compressive, may promote or prevent the impurity incorporation. Earlier, it was reported, that the tensile in plane stress favours Ga incorporation into $\mathrm{ZnO}$ [31]. Our XRD data, obtained for films on different substrates but at the same Cd content in the target, clarify these issues as following. Both lattice mismatch between $\mathrm{Si}$ and $\mathrm{ZnO}(\sim 40 \%$ [32]) and $\mathrm{Al}_{2} \mathrm{O}_{3}$ and $\mathrm{ZnO}$ (18\% or $31.8 \%$ in the case of in-plane twist at high temperature growth [33]) are rather significant. 


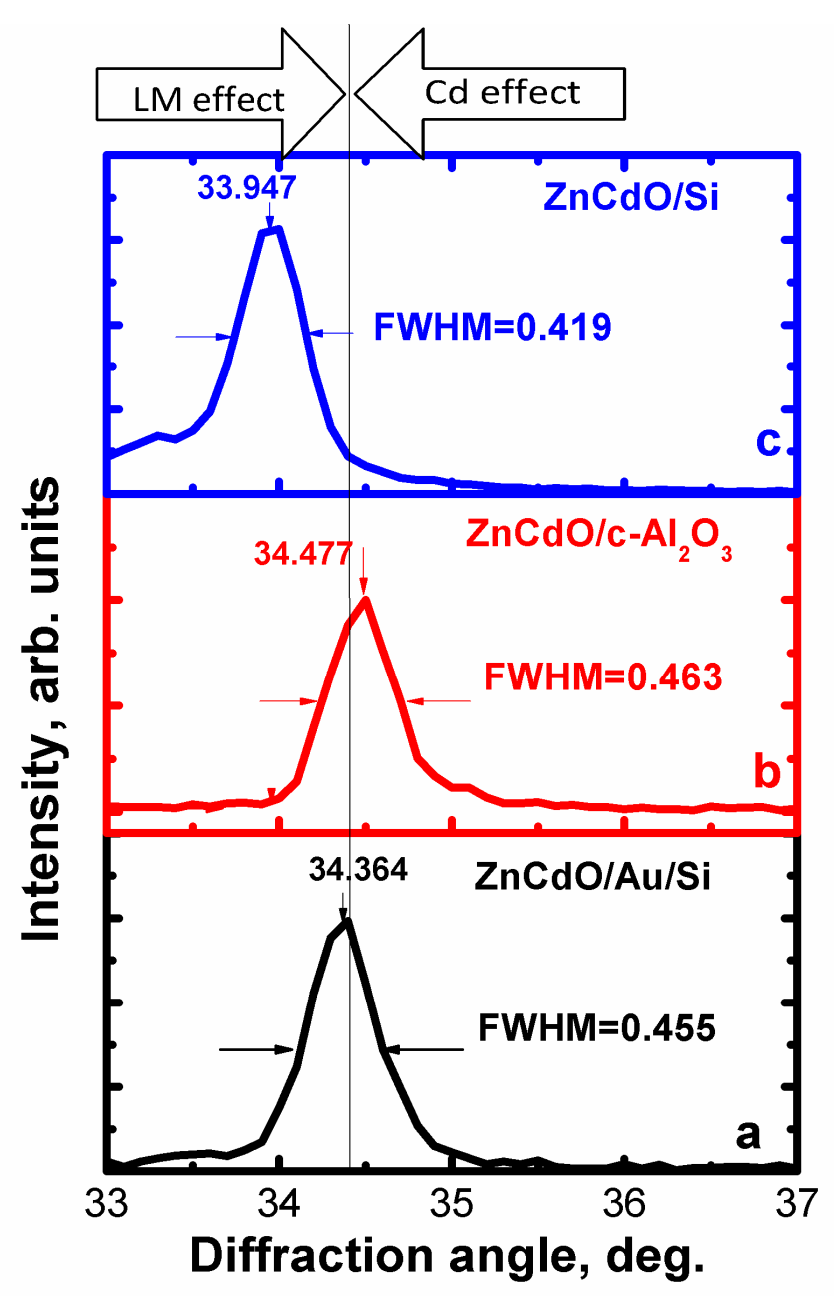

Fig. 2 XRD patterns in the $2 \theta$ range of $33^{\circ}-37^{\circ}$ of $Z n_{1-x} C d_{x} O$ films grown on three substrates: (a) $\mathrm{Au}$-coated $\mathrm{Si},(b) \mathrm{p}$-Si and (c) $c-\mathrm{Al}_{2} \mathrm{O}_{3}$. On the top of the image the respective effect of lattice mismatch and Cd incorporation effect on position of (002) peak is shown. The vertical line is a position of (002) peak for strain free $\mathrm{ZnO}$.

However, as a result of used growth techniques, the obtained films are polycrystalline, which byturn leads to mitigation of the lattice mismatch by large extent. Therefore, we claim that in our case $\mathrm{Cd}$ incorporation by itself is most influential factor on the structural characteristics of the $\mathrm{ZnO}$ films. Due to the $\mathrm{Cd}$ and $\mathrm{Zn}$ ionic radii - $0.97 \AA$ in comparison to $0.74 \AA$, when Cd substitutes $\mathrm{Zn}$ in his lattice sites, both $a$ and $c$ lattice parameters are enlarged. For the hexagonal lattice the position of the (002) reflection is directly related to the $c$-lattice parameter via the diffraction angle as following [34]: 


$$
\mathrm{c}=\frac{\lambda}{\sin \theta}
$$

where $\lambda$ is the $\mathrm{CuKa} \alpha_{1}$ radiation, and $\theta$ is the diffraction angle. Thus, the $\mathrm{Cd}$ incorporation should increase the $c$ value. While in the case of epitaxial growth both substrates should decrease the clattice parameter (due to expected tensile in-plane stress [35]) and thus, the (002) peak should occur toward the higher diffraction angles. However, as one can see, in our case for $\mathrm{Si}$ and $\mathrm{Au} / \mathrm{Si}$ substrates, the (002) peaks are shifted toward smaller diffraction angles, thereby evidencing the increase of c-parameter (Fig. 2). This increase of $c$-lattice parameter is associated with $\mathrm{Cd}$ incorporation and is agreed in a previous report [36]. However, the substrate by itself affects the average $\mathrm{Cd}$ content. While for the case of sapphire substrate, the effect of substrate (lattice mismatch (LM) effect) is more influential. Apparently, the (002) peak has been initially shifted toward higher diffraction angles. It is owing to tensile in plane strain provided by the substrate. And afterwards - being compensated by $\mathrm{Cd}$ incorporation - it underwent the shift toward opposite direction. It is generally known that the considerable difference in the lattice periods between the film and the substrate will lead to an appearance of compressive stresses. $\mathrm{ZnO}$ films grown on $c$ Al2O3 substrates always undergo serious residual strain induced by the lattice mismatch $\left[a_{\mathrm{Al2O} 3}-a_{\mathrm{ZnO}}\right] / a_{\mathrm{Al} 2 \mathrm{O} 3}=-18.3 \%$ [37] and the difference of coefficient of thermal expansion (CTE): $\left[\mathrm{CTE}_{\mathrm{Al} 2 \mathrm{O} 3}-\mathrm{CTE}_{\mathrm{ZnO}}\right] / \mathrm{CTE}_{\mathrm{Al} 203}=-34 \%$ [37]. Cadmium incorporation will lead to the lattice expansion and will cause the appearance of the tensile stresses. It is due to the difference in ionic radii between zinc and cadmium [38]. Therefore, the (002) peak of the $\mathrm{ZnO}$, which is grown on the sapphire, is always shifted towards the side of larger Bragg angles due to the compressive stresses. When the solid solution is formed, the (002) peak will displace towards the side of the smaller Bragg angles due to the compensation effect of the residual compressive stresses by the tensile stresses. Fig. 2 also demonstrates the value of the FWHM (full width on half maximum) for films grown on the different substrates. It was revealed that different samples have different values of FWHM. It may be explained as follows. It is well known that the broadening of the 002 peak is produced by either lattice strains alone, or by lattice strains and small particle size simultaneously 
[39]. Therefore, the different values of the FWHM for different samples are associated with the individual features of the substrate (lattice and/or TCE mismatch with film, individual rate of surface diffusion process, thermal conductivity), which can promote (i) growth of large or small grains and (ii) appearance of tensile (or compressive) strain. That's why; the films deposited on different substrates demonstrate different FWHM values.

On the other hand, different compositional fluctuations in the samples can also be a reason for difference in FWHM values. In fact, it is very difficult to choose a dominant factor. There are several competing and complementary mechanisms.

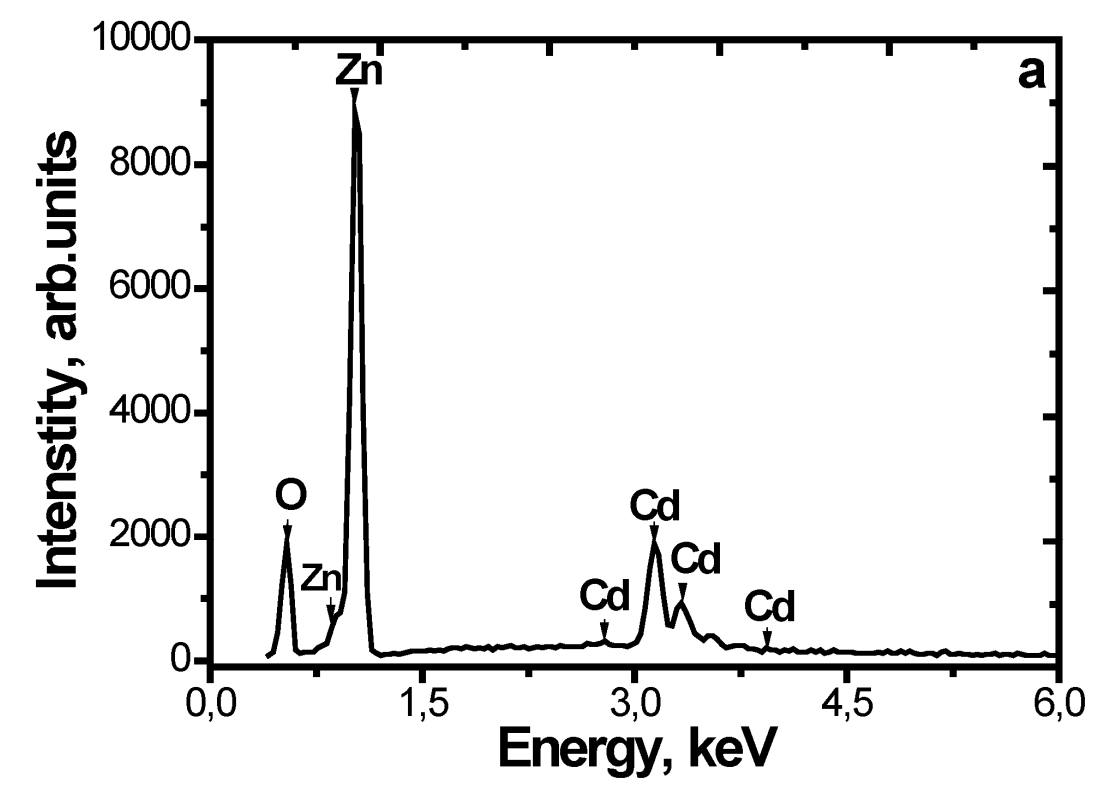

Fig. 3 EDX spectrum of the ZnCdO film grown on Au-coated Si.

Moreover, the spectral location of the peak was found to be in correlation with the $\mathrm{Cd}$ content, determined by EDX analysis (Table 2). Thus, we can pre-conclude, that the Cd incorporation effect is dominant on the lattice parameters of $\mathrm{ZnO}$. Fig. 3 demonstrates the typical EDX spectrum of the $\mathrm{ZnCdO} / \mathrm{Au}$-coated $\mathrm{Si}$, which reveals that the sample is composed of $\mathrm{O}, \mathrm{Zn}$, and $\mathrm{Cd}$.

TABLE 2 

well as microstructure parameters of the ZnCdO ternary alloys deposited on the different substrates

\begin{tabular}{|c|c|c|c|c|c|c|c|}
\hline \multirow{2}{*}{ Sample } & \multicolumn{2}{|c|}{$\begin{array}{c}\text { Atomic content of } \\
\text { elements with } \\
\text { errors, at. }\end{array}$} & $\begin{array}{c}\text { Stoichiometry } \\
\text { ratio, } \\
\text { O/(Zn+Cd) }\end{array}$ & $\begin{array}{c}\text { c-lattice } \\
\text { parameter, } \\
\AA\end{array}$ & $\begin{array}{c}\text { Strain, } \\
\boldsymbol{\varepsilon}^{\cdot \mathbf{1 0}^{-3}}\end{array}$ & $\begin{array}{c}\text { Crystallite } \\
\text { size } \boldsymbol{D}, \mathbf{n m}\end{array}$ \\
\cline { 2 - 8 } & $\mathbf{O}$ & $\mathbf{Z n}$ & $\mathbf{C d}$ & & & & \\
\hline $\mathrm{ZnCdO} / \mathrm{Au} / \mathrm{Si}$ & $52 \pm 1$ & $42 \pm 1$ & $6 \pm 0.1$ & 1.08 & 5.215 & +1.84 & 19 \\
\hline $\mathrm{ZnCdO} / \mathrm{c}-\mathrm{Al}_{2} \mathrm{O}_{3}$ & $48 \pm 1$ & $47 \pm 1$ & $5 \pm 0.1$ & 0.92 & 5.199 & -1.23 & 18 \\
\hline $\mathrm{ZnCdO} / \mathrm{Si}$ & $51 \pm 1$ & $40 \pm 1$ & $8 \pm 0.1$ & 1.04 & 5.277 & +13.7 & 21 \\
\hline
\end{tabular}

A simultaneous influence of both $\mathrm{Cd}$ incorporation and substrate type on the crystal lattice leads to the strain along c-axis in $\mathrm{ZnCdO}$ films. The strain value can be estimated by following formula: $\varepsilon=\left(c_{\text {film }}-c_{\text {bulk }}\right) / c_{\text {bulk }}$, where $c_{\text {bulk }}=5.2054 \mathrm{~nm}$. Crystallite sizes were calculated by the Debye-Scherrer method [40]:

$$
D=\frac{0.94 \lambda}{\beta \cos \theta}
$$

Lattice parameters, crystallites sizes, and strain values determined from the XRD data of all samples are also presented in Table 2. As one can see from the Table 2, a clear correlation exists between the atomic content of $\mathrm{Cd}$ and the c-lattice parameter. The different cadmium content of the resultant films on Au-coated $\mathrm{Si}$, bare $\mathrm{Si}$ and sapphire may be related to the lattice structure and defects on the substrate surface, which is an important factor, governing the chemically adsorption and subsequent nucleation and growth [41]. We supposed that the highest $\mathrm{Cd}$ incorporation (8.61 at.\%), observed for $\mathrm{Zn}_{1-\mathrm{x}} \mathrm{Cd}_{\mathrm{x}} \mathrm{O}$ grown on $\mathrm{Si}$ substrate, may be associated with the fact that the thermal conductivity of $\mathrm{Si}$ is better than that of sapphire. Wei et al. [42] have revealed that the difference in thermal conductivity may be a possible reason that the best growth temperature $\left(400{ }^{\circ} \mathrm{C}\right)$ of $\mathrm{ZnO}$ thin film fabricated on $\mathrm{Si}$ substrate is lower than that of sapphire $\left(500^{\circ} \mathrm{C}\right)$. Since the growth procedure in our experiment was realized at the substrate temperature of $400{ }^{\circ} \mathrm{C}$ then the Cd incorporation is favored in the Si substrate. 


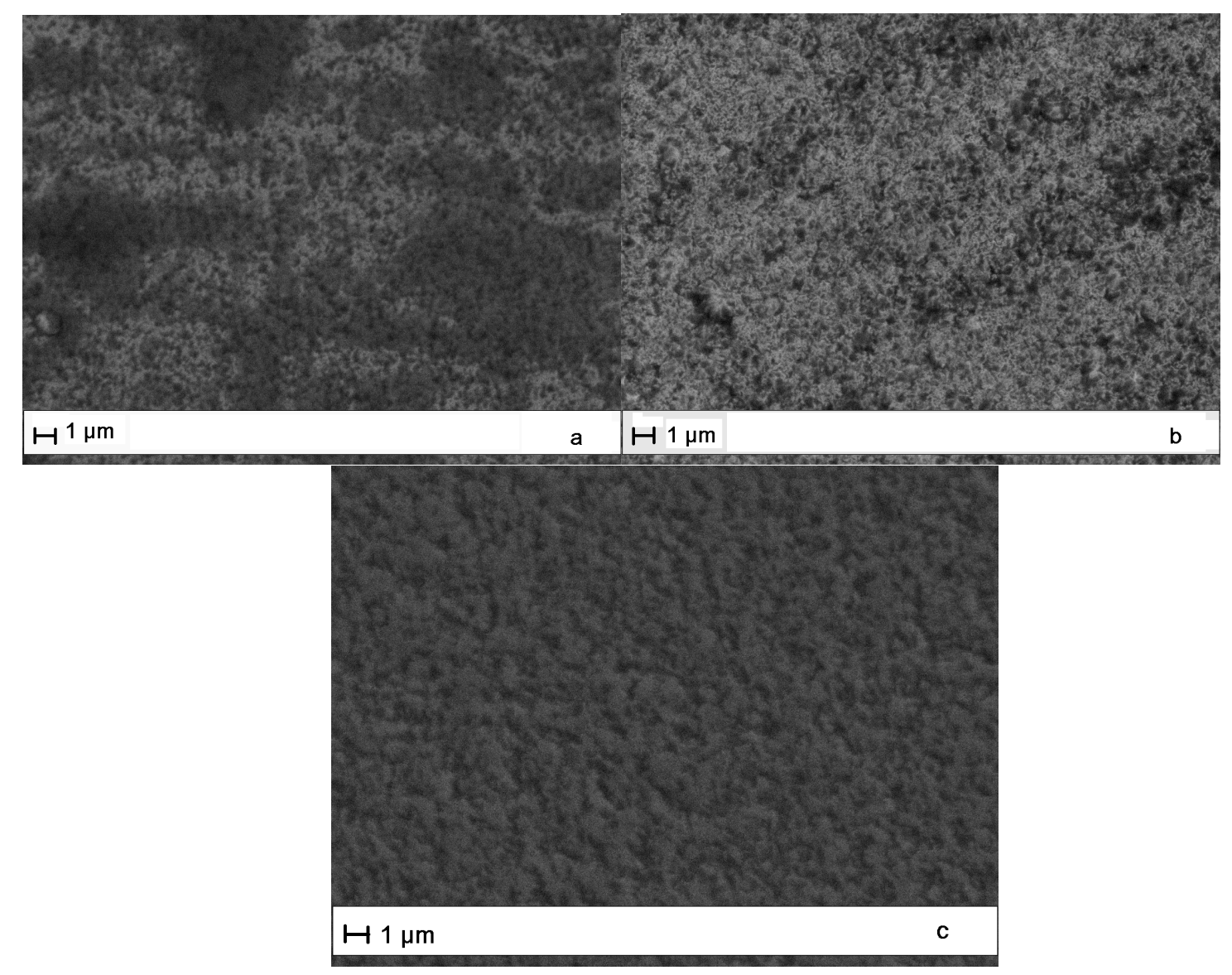

Fig. 4 SEM images of the ZnCdO films grown on the various substrates: (a)Au-coated Si, (b) c-

$$
\mathrm{Al}_{2} \mathrm{O}_{3} \text { and (c) } \mathrm{Si}
$$

The microstructural properties of $\mathrm{ZnCdO}$ films deposited on different substrates are shown in Fig. 4. The films in general demonstrate the microstructure, peculiar for sputtered films - dense coverage of grains, which are not hexagonally faceted - which is probably due to high deposition rate and low growth temperature. For all the films rather rough surface was observed. The film, deposited on sapphire, is slightly different in comparison to others: the grains are better resolved and can be identified more clearly. This is correlated with XRD and EDX results, which revealed that the film grown on $\mathrm{Al}_{2} \mathrm{O}_{3}$ is characterized by smallest value of the strain and smallest cadmium content in comparison to other films. The observed rough morphology of the films may be vital for their application as a top layer for the solar cells. Particularly, surface morphology is an important characteristic of $\mathrm{ZnO}$ films within such area of application as silicon thin film solar cells. It should 
be noted that the developed surface texture is required to provide light scattering and subsequent light trapping inside the silicon solar cell structure [43].

The possible difference in structural properties between samples grown on $\mathrm{Au}$-coated $\mathrm{Si}, \mathrm{Si}$ and sapphire substrates may be explained by the fact that the every substrate associated with an individual rate of surface diffusion process. It is well known that the mass transport may occur during crystal growth through surface diffusion process of the adatoms, which is governed by surface kinetics and is strongly dependent on substrate types [44]. So, we have concluded that the Au-coated Si, Si and sapphire substrates are characterized by the different values of the time which described a duration the adatoms undergoes in the diffusion process. In other words, this time may be the time the adatoms spend on the surface either before being captured in the lattice site or desorbed from the surface [44]. Apparently, the desorption processes of the Cd adatoms are most intense for the film which was condensed on the sapphire substrate. In particular, it agrees well with EDX results. The newly arrived $\mathrm{Cd}$ species have no time in order to take place the thermodynamic lattice sites, thereby promoting the cadmium accumulation at the grain boundaries [45]. 

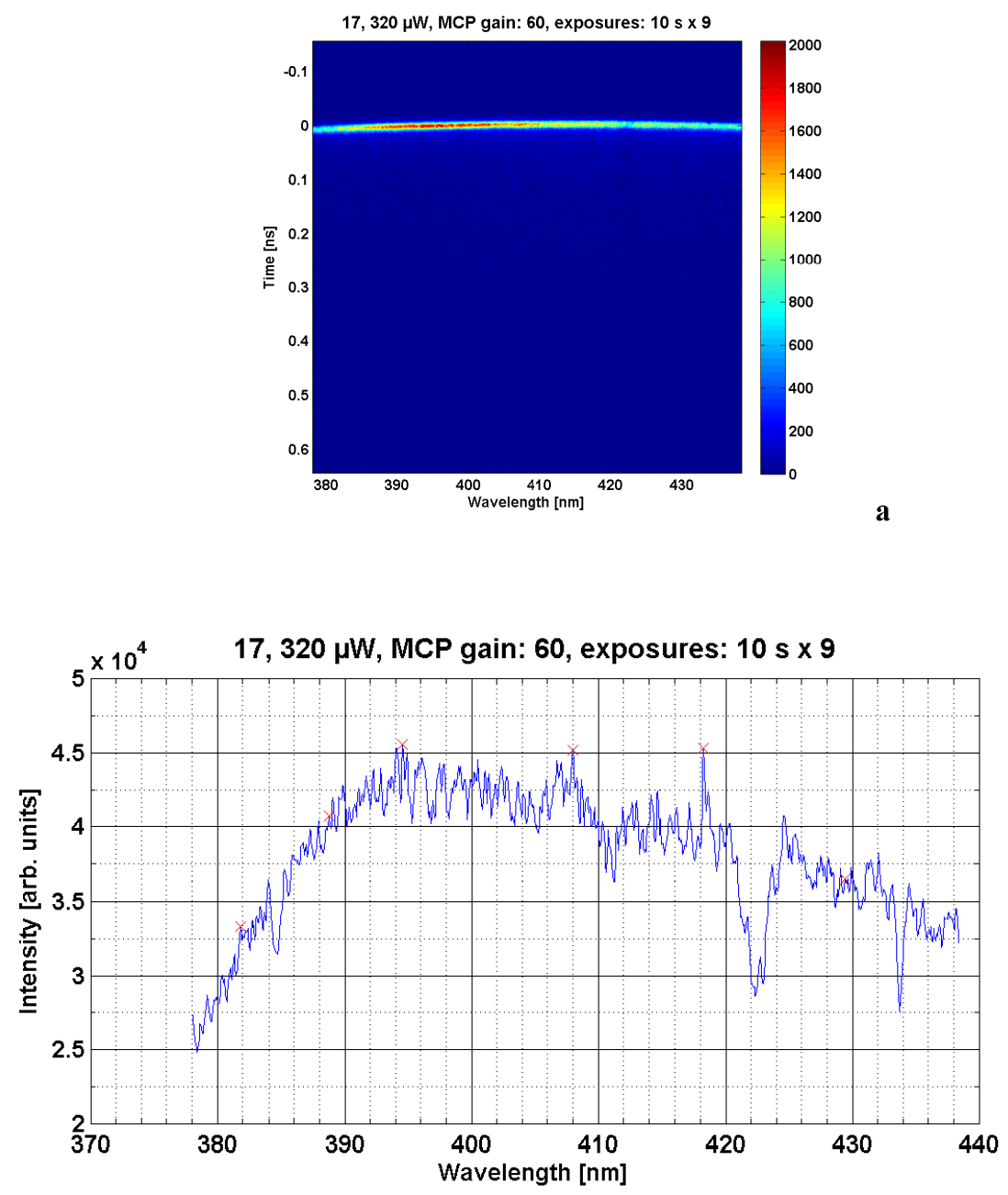

b

$388.78 \mathrm{~nm}$

alpha $=[1.735 \mathrm{e}+0037.230 \mathrm{e}+004]$ arb. units, tau $=[0.1020 .005] \mathrm{ns}$, beta $=\left[\begin{array}{ll}1.000 & 1.000\end{array}\right]$

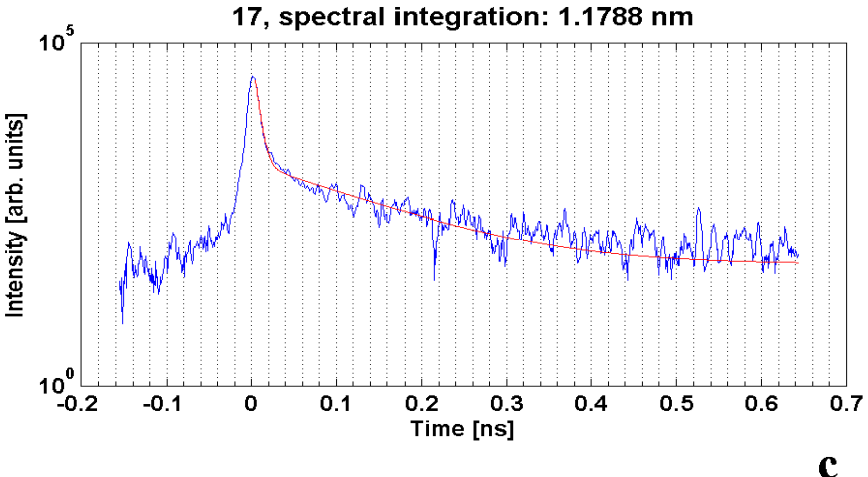

Fig. 5 The PL dynamics of the $\mathrm{ZnCdO/} \mathrm{Al}_{2} \mathrm{O}_{3}$ sample: time resolved PL image (a), taken for the spectral range (b) and the decay time curve (c), fitted respectively. 
In order to gain insight into the origin of the radiative recombination, we have performed time-resolved PL measurements (TRPL) of the samples $\mathrm{ZnCdO} / \mathrm{Au} / \mathrm{Si}, \mathrm{ZnCdO} / \mathrm{Si}$ and $\mathrm{ZnCdO} / \mathrm{Al}_{2} \mathrm{O}_{3}$ at room temperatures. The time decay has been studied integrated for the band as wide as $380 \div 430 \mathrm{~nm}$. Figure 5, for example, demonstrates the PL dynamics of the $\mathrm{ZnCdO} / \mathrm{Al}_{2} \mathrm{O}_{3}$ sample: time resolved PL image (a), taken for the spectral range (b) and the decay time curve (c), fitted respectively. The decaying part of the TRPL data was well described by the bi-exponential decay function: $\mathrm{I}(\mathrm{t})=\mathrm{A}_{1} \exp \left(-\mathrm{t} / \tau_{1}\right)+\mathrm{A}_{2} \exp \left(-\mathrm{t} / \tau_{2}\right)$ [46]. Thus, analysis of the decay curves by means of the mentioned function gives a possibility to extract time constants $\tau_{1}$ and $\tau_{2}$ depending on the Cd content, which defines by the substrate type (as shown in Table 2). It should be mentioned that the decay time constants are different for the studied samples.

The sample on sapphire demonstrated the decay time constants $\tau_{1} \sim 9$ ps and $\tau_{2}=121 \pm 18$ ps. For the sample of $\mathrm{ZnCdO}$ on bare $\mathrm{Si} \tau_{1}=30 \pm 9$ ps (depending on the position on the sample), while $\tau_{2}=220 \pm 20 \mathrm{ps}$. While for the sample $\mathrm{ZnCdO}$ on $\mathrm{Au} / \mathrm{Si}$ substrate, the $\tau_{1}=29 \pm 10 \mathrm{ps}$ and $\tau_{2}=$ $240 \pm 45$ ps. These time constants are comparable to those of $\mathrm{ZnCdO}$ reported earlier by Yang et al. [47]. An initial fast decay component $\tau_{1}=\tau_{\mathrm{NR}}$ is attributed to the capture of excitons and trapping of carriers by deep centers of defects and impurities (centers of the non-radiative recombination) and process of the multiphonon emission [48]. A slow decay component $\tau_{2}=\tau_{\mathrm{R}}$ describes the lifetime of radiative recombination for both free and localized excitons [48]. The exciton recombination time at RT is most likely determined by nonradiative recombination as the obtained values are comparable to the free exciton lifetime $(0.03-0.11 \mathrm{~ns})$ measured at RT from $\mathrm{ZnO}$ epilayers but are substantially shorter than that for bulk $\mathrm{ZnO}$ ( $~ 1 \mathrm{~ns}$ ) with low defect density [49]. For $\mathrm{ZnO}$ thin films, earlier it was shown that the bound exciton decay time is dependent on the grain size and it varied from 47 ps for $40 \mathrm{~nm}$ grains to 216 ps for $200 \mathrm{~nm}$ grains [50]. Thus, the difference in our case between samples grown on $\mathrm{Si}$ and sapphire substrates may be explained as due to that. Interesting is the observed effect of $\mathrm{Au}$ on the decay time of $\mathrm{ZnCdO}$ samples, grown on $\mathrm{Au}$ coated Si substrate. Earlier, Au has been reported responsible for passivation of the non-radiative recombination centers 
in $\mathrm{ZnO}$, increasing the decay time significantly. Yang et al. has reported that that the Au particles can greatly reduce the nonradiative recombination rate by passivation of surface states and make the decay time slow down [47]. Additionally, we can find the internal quantum efficiency of $\mathrm{ZnCdO}$ $\eta_{\text {int }}(\mathrm{ZnCdO})$, which can be described as: $\eta_{\text {int }}=\left(1 / \tau_{\mathrm{R}}\right) /\left[\left(1 / \tau_{\mathrm{R}}\right)+\left(1 / \tau_{\mathrm{NR}}\right)\right]$ [47]. Calculated parameters are shown in the Table 3.

It should be noted that we found a correlation between the $\mathrm{Cd}$ content and quantum efficiency (as shown in Table 3). The film with the largest cadmium content demonstrates the largest value of the internal quantum efficiency. It may be caused by several factors: (i) decrease in the concentration of the intrinsic point defects, which may play a role of the non-radiative recombination centers and (ii) strong exciton localization, which can be a reason for the enhancement of the probability of the radiative transitions [51].

Table 3.

Parameters extracted from TRPL data and value of deviation from stoichiometric ratio

\begin{tabular}{|c|c|c|c|}
\hline \multirow{2}{*}{ Parameters } & \multicolumn{3}{|c|}{ Substrate type } \\
\cline { 2 - 4 } & $\mathbf{c}^{-} \mathbf{A l}_{\mathbf{2}} \mathbf{O}_{\mathbf{3}}$ & $\mathbf{S i}$ & $\mathbf{A u} / \mathbf{S i}$ \\
\hline$\tau_{1}=\tau_{\mathrm{NR}}$ & 9 & 30 & 29 \\
\hline$\tau_{2}=\tau_{\mathrm{R}}$ & 121 & 220 & 240 \\
\hline Internal quantum efficiency $\eta$ & 0.069 & 0.119 & 0.107 \\
\hline Cd content, at.\% & $5 \pm 0.1$ & $8 \pm 0.1$ & $6 \pm 0.1$ \\
\hline Deviation from the stoichiometry, $\Delta \mathrm{S}$ & -0.08 & 0.04 & 0.08 \\
\hline
\end{tabular}

Taking into account the first factor (i), we have found a principle relationship between the value of the deviation of the stoichiometric ratio $\Delta \mathrm{S}$, which may be expressed as: $\Delta \mathrm{S}=\mathrm{n}_{\mathrm{O}} /\left(\mathrm{n}_{\mathrm{Zn}}+\mathrm{n}_{\mathrm{Cd}}\right)-1$, and cadmium content in the film (Fig. 6). The film with the smallest cadmium content $(5.1$ at. \%) is characterized by the negative magnitude $\Delta \mathrm{S}$ of -0.08 (conditions of the oxygen deficiency). In these non-equilibrium conditions, the intrinsic point defects associated with zinc excess, i.e., oxygen vacancies $\left(\mathrm{V}_{\mathrm{O}}\right)$ and zinc interstitials $\left(\mathrm{Zn}_{\mathrm{i}}\right)$, are lowered in formation energy [52]. On the other hand, the film with the largest cadmium content (8.6 at. \%) demonstrates a positive magnitude of the $\Delta \mathrm{S}$ value of +0.04 (conditions of the zinc deficiency). In this case, the point defects related to oxygen 
excess, i.e., zinc vacancies $\left(\mathrm{V}_{\mathrm{Zn}}\right)$ and oxygen interstitials $\left(\mathrm{O}_{\mathrm{i}}\right)$, are lowered in formation energy [52]. Thus, the Zn-rich conditions and/or O-rich conditions cause the lowering of the formation energy $E_{\mathrm{F}}$ of the corresponding defects and lead to an increase in the concentration of the corresponding intrinsic point defects. This statement is thoroughly valid, since the concentration of defects in a crystal depends upon its formation energy $E_{\mathrm{F}}$ in the following form [2]:

$$
\mathrm{C}=\mathrm{N}_{\text {sites }} \exp \left(-\mathrm{E}_{\mathrm{F}} / \mathrm{k}_{\mathrm{B}} \mathrm{T}\right) \text {, }
$$

where $\mathrm{N}_{\text {sites }}$ is the concentration of sites in the crystal where the defect can occur. Therefore, a high magnitude of the deviation from the stoichiometry implies the low formation energy and the high equilibrium concentration of the defects. In this case, the role of the non-radiative recombination processes starts to increase.

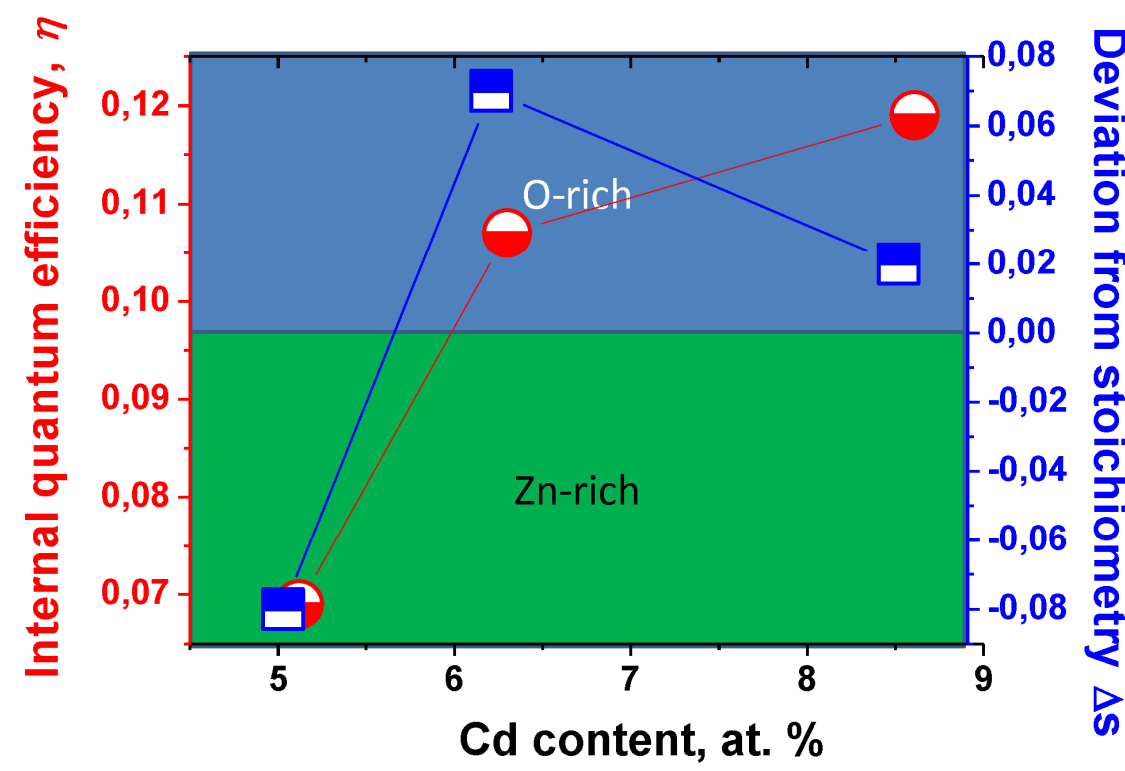

Fig. 6. Dependencies of the internal quantum efficiency (circles) and the value of the deviation from stoichiometric ratio (squares) on the cadmium content.

On the other hand, high formation energy means that the defects are unlikely to form. According to above-mentioned explanation the increase in $\mathrm{Cd}$ content leads to a reduction of the defect concentration. It is very strange. Nevertheless, we should take into account the fact that the cadmium ions, incorporating into $\mathrm{ZnO}$ matrix, may influence the energetics of the native defects in 
$\mathrm{ZnO}$ and may either lower the formation energy of the defects or raise the value of $E_{\mathrm{F}}$ depending on the deficiency (or enrichment) of the host atoms. Furthermore, in a previous work [53], which was devoted to InGaN (semiconductor analogue of $\mathrm{ZnCdO}$ ), it was shown that the indium may sufficiently reduce the density of the non-radiative recombination centers $\mathrm{N}_{t}$, thereby decreasing the probability of the non-radiative optical transitions $1 / \tau_{\text {non-rad. }}$ Physical relationship between mentioned parameters may be expressed by means of the following formula [53]:

$$
1 / \tau_{\text {non-rad }}=\mathrm{V}_{\mathrm{th}} \cdot \sigma \cdot \mathrm{N}_{\mathrm{t}}
$$

where $V_{\text {th }}$ is the thermal velocity, $\sigma$ is the cross section captured by the non-radiative recombination center. Thus, $\mathrm{N}_{\mathrm{t}}$ value was greatly suppressed by the addition of a small amount of In [53]. A similar mechanism of the passivation of the point defects may be also realized in $\mathrm{ZnCdO}$ semiconductor system. However, this assumption requires the additional experimental support.

Taking into account the second factor of the influence - (ii) strong exciton localization - on the internal quantum efficiency of $\mathrm{ZnCdO}$, it should be mentioned that the increase in $\mathrm{Cd}$ content may cause the large composition fluctuations (large localization depth) and may lead to appearance of the great number of potential minima, which could capture the excitons, thereby increasing the probability of the processes of radiative annihilation and blocking the nonradiative optical transitions. Indeed, it was previously reported [54-56] that the effect of the exciton localization induced by compositional fluctuation of In leads to the hindering the pathways of nonradiative recombination centers and capturing the excitons at potential minima. Thus, we have revealed that the internal quantum efficiency are influenced by the $\mathrm{Cd}$ content and defect concentration, which are depending on the type of the substrate.

\section{Conclusions}

In summary, we have studied the microstructure and dynamics of luminescence of $\mathrm{Zn}_{1-\mathrm{x}} \mathrm{Cd}_{\mathrm{x}} \mathrm{O}$ films, with the Cd concentration over the solubility limit, deposited by dc MS on different substrates. It was shown that the $\mathrm{Cd}$ content has dominant effect on the structural properties of $\mathrm{ZnO}$ in terms of lattice parameters and available strains. However, the type of the substrate does affect the average $\mathrm{Cd}$ incorporation into $\mathrm{ZnO}$ films. It was found that the luminescence kinetics of $\mathrm{Zn}_{1-\mathrm{x}} \mathrm{Cd}_{\mathrm{x}} \mathrm{O}$ films 
was strongly dependent upon the substrate type and cadmium content and was well described by a bi-exponential. The occurrence of bi-exponential kinetics leads to the presence of the different mechanisms for excitonic recombination. We showed using time-resolved photoluminescence measurements that the internal quantum efficiency increases with increasing the cadmium content in the solid solution. We explained this behavior in the context of strong exciton localization as well as blocking the pathways of nonradiative recombination centers. This effect may be useful for the enhancement of the emission efficiency of the $\mathrm{ZnCdO}$ solid solution due to limitation of exciton movement and increasing the probability of the radiative optical transitions. The reported data contribute significantly towards understanding the band engineering of $\mathrm{ZnO}$ toward visible range or design of quantum wells heterostructures based on $\mathrm{ZnCdO}$.

\section{Acknowledgements}

We greatly acknowledge the Linköping Linnaeus initiative for Novel Functional Materials (LiLiIFM) for the support of this work.

\section{References}

[1] G. V. Lashkarev, V. A. Karpyna, V. I. Lazorenko, A. I. Ievtushenko, I. I. Shtepliuk and V. D. Khranovskyy, Properties of zinc oxide at low and moderate temperatures, Low Temp. Phys. 37 (2011) 226-234.

[2] Ü.Özgür, Ya. I. Alivov, C. Liu, A.Teke, M. A. Reshchikov, S. Doğan, V. Avrutin, S.-J. Cho, H. Morkoç, A comprehensive review of $\mathrm{ZnO}$ materials and devices, J. Appl. Phys. 98 (2005) 041301-103.

[3] F. Wang, Z. Ye, D. Ma, L. Zhu, F. Zhuge, Formation of quasi-aligned ZnCdO nanorods and nanoneedles, J. Cryst. Growth 283 (2005) 373-377.

[4] I. Shtepliuk, G. Lashkarev, V. Khomyak, O. Lytvyn, P. Marianchuk, I. Timofeeva, A. Ievtushenko, V. Lazorenko, Features of the influence of the deposition power and $\mathrm{Ar} / \mathrm{O}_{2}$ gas ratio on the microstructure and optical properties of the $\mathrm{Zn}_{0.9} \mathrm{Cd}_{0.1} \mathrm{O}$ films, Thin Solid Films 520 (2012) $4772-4777$.

[5] T. Makino, Y. Segawa, M. Kawasaki, A. Ohtomo, R. Shiroki, K. Tamura, T. Yasuda, and H. 
Koinuma, Band gap engineering based on MgxZn1-xO and CdyZn1-yO ternary alloy films, Appl. Phys. Lett. 78 (2001) 1237-1239.

[6] F. Fang, D. Zhao, X. Fang, J. Li, Z. Wei, S. Wang, Jilong Wu, D. Shen, X. Wang, Tunable electroluminescence from n-ZnCdO/p-GaN heterojunction, J. Phys. Chem. Solids 73 (2012) 217220.

[7] W. Lim, D. P. Norton, S. J. Pearton, X. J. Wang, W. M. Chen, A. Buyanova, A. Osinsky, J. W. Dong, B. Hertog, A. V. Thompson, W. V. Schoenfeld, Y. L. Wang and F. Ren, Migration and luminescence enhancement effects of deuterium in $\mathrm{ZnO} / \mathrm{ZnCdO}$ quantum wells, Appl. Phys. Lett. $92(2008) 032103$.

[8] B. Liu, C. W. Cheng, R. Chen, S. A. Ekahana, W. F. Yang, S. J. Wang, T. C. Sum, Z. X. Shen, H. J. Fan, and H. D. Sun, Surface plasmon induced exciton redistribution in $\mathrm{ZnCdO} / \mathrm{ZnO}$ coaxial multiquantum-well nanowires, Appl. Phys. Lett. 97 (2010) 081107-3.

[9] I. Shtepliuk, V. Khranovskyy, G. Lashkarev, V. Khomyak, V. Lazorenko, A. Ievtushenko, M. Syväjärvi, V. Jokubavicius and R. Yakimova, Electrical properties of $\mathrm{n}-\mathrm{Zn}_{0.94} \mathrm{Cd} \mathrm{d}_{0.06} \mathrm{O} / \mathrm{p}-\mathrm{SiC}$ heterostructures, Solid-state electron. 81 (2013) 72-77.

[10] D.-H. Lee, S. Kim, S. Y. Lee, Zinc cadmium oxide thin film transistors fabricated at room temperature, Thin Solid Films 519 (2011) 4361-4365

[11] K. Yamamoto, T. Tsuboi, T. Ohashi, T. Tawara, H. Gotoh, A. Nakamura, J. Temmyo, Structural and optical properties of $\mathrm{Zn}(\mathrm{Mg}, \mathrm{Cd}) \mathrm{O}$ alloy films grown by remote-plasma-enhanced MOCVD, J. Cryst. Growth. 312 (2010) 1703-1708.

[12] K. Yamamoto, M. Adachi, T.Tawara, H. Gotoh, A. Nakamura, J. Temmyo, Synthesis and characterization of $\mathrm{ZnCdO} / \mathrm{ZnO}$ multiple quantum wells by remote-plasma-enhanced MOCVD, J. Cryst. Growth 312 (2010) 1496-1499

[13] I. A. Buyanova, J. P. Bergman, G. Pozina, W. M. Chen, S. Rawal, Mechanism for radiative recombination in ZnCdO alloys, Appl. Phys. Lett. 90 (2007) 261907-3.

[14] T. Singh, D.K. Pandya, R. Singh, Synthesis of cadmium oxide doped ZnO nanostructures using electrochemical deposition, J. Alloys Compd. 509 (2011) 5095-5098. 
[15] A. Fouzri, V.Sallet, M.Oumezzine A comparative structure and morphology study of $\mathrm{Zn}(1-$ $\mathrm{x}) \mathrm{CdxO}$ solid solution grown on $\mathrm{ZnO}$ and different sapphire orientations, J. Cryst. Growth 331 (2011) 18-24.

[16] A. Singh, D. Kumar, P.K. Khanna, B. Chander Joshi, M. Kumar, Effect of post annealing temperature on structural and optical properties of $\mathrm{ZnCdO}$ thin films deposited by sol-gel method, Appl. Surf. Sci. 258 (2011) 1881- 1887.

[17] B.J. Zheng, J.S. Lian, L. Zhao, Q. Jiang, Structural, optical and electrical properties of Zn1-xCdxO thin films prepared by PLD, Appl. Surf. Sci. 257 (2011) 5657-5662.

[18] F. Yakuphanoglu, S. Ilican, M. Caglar, Ya. Caglar, Microstructure and electro-optical properties of sol-gel derived Cd-doped ZnO films, Superlattices Microstruct. 47 (2010) 732-743.

[19] D.W. Ma, Z.Z. Ye, Y.S. Yang, A comparative study on Zn0.8Cd0.2O films deposited on different substrates, Appl. Surf. Sci. 252 (2006) 5051-5056

[20] R.J. Kennedy, P.A. Stampe, The influence of lattice mismatch and film thickness on the growth of TiO2 on LaAlO3 and SrTiO3 substrates, Journal of Crystal Growth 252 (2003) 333-342. [21] Y.-C. Lee, S.-Y. Hu, W. Water, K.-K. Tiong, Z.-C. Feng, Y.-T. Chen, J.-C. Huang, J.-W. Lee, C.-C. Huang, J.-L. Shen, M.-H. Cheng, Rapid thermal annealing effects on the structural and optical properties of $\mathrm{ZnO}$ films deposited on Si substrates, J. Lumin., 129 (2009) 148-152

[22] Cole W. Litton, Donald C. Reynolds, Thomas C. Collins, Zinc oxide materials for electronic and optoelectronic device applications, Wiley, West Sussex, 2011, p.224.

[23] S. M. Sze, The Physics of Semiconductor Devices, Wiley, New York, 1969, pp. 12-20.

[24] R. Hull, Properties of Crystalline Silicon, INSPEC, London, 1999.

[25] A. O’Mahony, S. Monaghan, G. Provenzano, I. M. Povey, M. G. Nolan, É. O’Connor, K. Cherkaoui, S. B. Newcomb, F. Crupi, P. K. Hurley, and M. E. Pemble, Structural and electrical analysis of the atomic layer deposition of $\mathrm{HfO} 2 / n$-In0.53Ga0.47As capacitors with and without an A12O3 interface control layer, Appl. Phys. Lett. 97 (2010) 052904-3

[26] International Centre for Diffraction Data (ICDD) card number 42-1468.

[27] V. Khranovskyy V, I. Tsiaoussis, L. Hultman L and R. Yakimova, Selective homoepitaxial 
growth and luminescent properties of ZnO nanopillars, Nanotechnology 22 (2011) 185603.

[28] B. Ma, G.K.L. Goh, J. Ma, T.J. White, Growth Kinetics and Cracking of Liquid- PhaseDeposited Anatase Films, J. Electrochem. Soc. 154 (2007) D557.

[29] J. J. Brown and F.A. Hummel, Phase Equilibria and Manganese-Activated Luminescence in the Systems CdO-P2O5 and Zn2P2O7-Cd2P2O7; Summary for the System ZnO-CdO-P2O5, J. Electrochem. Soc. 111 (1964) 1052-1057.

[30] V. Khranovskyy, R. Minikayev, S. Trushkin, G. Lashkarev, V. Lazorenko, U. Grossner, W.

Paszkowicz, A. Suchocki, B. G. Svensson, R. Yakimova, Improvement of ZnO thin film properties by application of ZnO buffer layers, J. Cryst. Growth 308 (2007) 93-98.

[31] A.R. Kaul, O.Yu. Gorbenko, A.N. Botev, L.I. Burova, MOCVD of pure and Ga-doped epitaxial ZnO, Superlattices Microstruct. 38 (2005) 272-282.

[32] L. Xu, L. Shi, X. Li, Effect of TiO2 buffer layer on the structural and optical properties of $\mathrm{ZnO}$ thin films deposited by E-beam evaporation and sol-gel method, Appl. Surf. Sci. 255 (2008) 32303234

[33] B. P. Zhang, K. Wakatsuki, N. T. Binh, N. Usami, and Y. Segawa, Effects of growth temperature on the characteristics of $\mathrm{ZnO}$ epitaxial films deposited by metalorganic chemical vapor deposition, Thin Solid Films, 449 (2004) 12-19.

[34] V.V. Khomyak, M.M. Slyotov, I.I. Shtepliuk, G.V. Lashkarev, O.M. Slyotov, P.D. Marianchuk, V.V. Kosolovskiy, Annealing effect on the near-band edge emission of ZnO, J. Phys. Chem. Solids, 74 (2013) 291-297.

[35] V. Khranovskyy, U. Grossner, V. Lazorenko, G. Lashkarev, B.G. Svensson, R. Yakimova, Study of annealing influence on electrical and morphological properties of $\mathrm{ZnO}$ :Ga thin films Physica Status Solidi C, 3 (2006) 780-784.

[36] D.W. Ma, Z.Z. Ye, H.M. Lu, J.Y. Huang, B.H. Zhao, L.P. Zhu, H.J. Zhang, P.M. He, Sputtering deposited ternary Zn1-xCdxO crystal films on Si(111) substrates, Thin Solid Films 461 (2004) 250-255

[37] S. H. Park, T. Hanada, D. C. Oh, T. Minegishi, H. Goto, G. Fujimoto, J. S. Park, I. H. Im, J. 
H. Chang, M. W. Cho, T. Yao and K. Inaba, Lattice relaxation mechanism of ZnO thin films grown on c-A12O3 substrates by plasma-assisted molecular-beam epitaxy, Appl. Phys. Lett. 91 (2007) 231904-3.

[38] Z. Ye, D. Ma, J. He, J.Huang, B. Zhao, X. Luo, Z. Xu Structural and photoluminescent properties of ternary Zn1-xCdxO crystal films grown on $\operatorname{Si}\left(\begin{array}{lll}1 & 1 & 1\end{array}\right)$ substrates, J. Cryst.Growth 256 (2003) 78-82.

[39] G.K. Williamson and W.M. Hall, X-ray line broadening from filed aluminium and wolfram, Acta Metall. 1 (1953) 22-31.

[40] B. Williamson, R.C. Smallman, Dislocation densities in some annealed and cold-worked metals from measurements on the X-ray debye-scherrer spectrum, Philos. Mag. 1 (1956) 34.

[41] J.Yang, J. Lang, L. Yang, Y. Zhang, D. Wang, H. Fan, H. Liu, Y. Wang, M. Gao, Low temperature growth and optical properties of ZnO nanorods, J. Alloys Compd. 450 (2008) 521. [42] X.Q. Wei, J.Z. Huang, M.Y. Zhang, Y. Du, B.Y. Man, Effects of substrate parameters on structure and optical properties of $\mathrm{ZnO}$ thin films fabricated by pulsed laser deposition, Mater. Sci. Eng. B 166 (2010) 141-146.

[43] V. Khranovskyy, A. Ulyashin, G. Lashkarev, B.G. Svensson, R. Yakimova, Morphology, electrical and optical properties of undoped $\mathrm{ZnO}$ layers deposited on silicon substrates by PEMOCVD, Thin Solid Films 516 (2008) 1396-1400.

[44] S.R. Haldar, A. Nayak, T.K. Chini, S. Bhuni/ Strong temperature and substrate effect on ZnO nanorod flower structures in modified chemical vapor condensation growth, Curr. Appl Phys. 10 (2010) 942-946.

[45] K. Sakurai, T.Takagi, T. Kubo, D. Kajita, T.Tanabe, H. Takasu, S. Fujita, S. Fujita, Spatial composition fluctuations in blue-luminescent $\mathrm{ZnCdO}$ semiconductor films grown by molecular beam epitaxy, J. Cryst. Growth 237 (2002) 514-517.

[46] A. Teke, Ü. Özgür, S. Doğan, X. Gu, H. Morkoc, B. Nemeth, J. Nause, and H. O. Everitt Excitonic fine structure and recombination dynamics in single-crystalline $\mathrm{ZnO}$, Phys. Rev. B. 70 (2004) 195207-10 
[47] W. F. Yang, R. Chen, B. Liu, G. G. Gurzadyan, L. M. Wong, S. J. Wang, and H. D. Sun, Surface-Plasmon enhancement of band gap emission from $\mathrm{ZnCdO}$ thin films by gold particles, Appl. Phys. Lett. 97 (2010) 061104.

[48] B. Guo, Zhizhen Ye, K.S. Wong, Time-resolved photoluminescence study of a ZnO thin film grown on a (1 0 0 $)$ silicon substrate, J. Cryst. Growth, 253 (2003) 252-257.

[49] T. Koida, S. F. Chichibu, A. Uedono, A. Tsukazaki, M. Kawasaki, T. Sota, and H. Koinuma, Correlation between the photoluminescence lifetime and defect density in bulk and epitaxial $\mathrm{ZnO}$, Appl. Phys. Lett. 82 (2003) 532.

[50]W. M. Kwok, A. B. Djurišić, Y. H. Leung, W. K. Chan, and D. L. Phillips, Time-resolved photoluminescence from ZnO nanostructures, Appl. Phys. Lett. 87 (2005) 223111.

[51]Y. Kawakami, A. Kaneta, K. Omae, A. Shikanai, K. Okamoto, G. Marutsuki, Y. Narukawa, T. Mukai, and Sg. Fujita, Recombination dynamics in low-dimensional nitride semiconductors, Phys. Stat. Sol. (b) 240 (2003) 337- 343.

[52] F. Oba, S. R. Nishitani, S. Isotani, and H. Adachi, I. Tanaka, Energetics of native defects in ZnO, J. Appl. Phys., 90/2 (2001) 824-828

[53] Yu. Narukawa, Sh. Saijou, Yo. Kawakami, Sh. Fujita, T. Mukai, and Sh. Nakamura, Radiative and nonradiative recombination processes in ultraviolet light-emitting diode composed of an In0.02Ga0.98N active layer, Appl. Phys. Lett. 74 (1999) 558-560.

[54] S. Chichibu, T. Azuhata, T. Sota, and S. Nakamura, Spontaneous emission of localized excitons in InGaN single and multiquantum well structures, Appl. Phys. Lett. 69 (1996) 4188.

[55] Y. Narukawa, Y. Kawakami, M. Funato, Sg. Fujita, and S. Nakamura, Role of self-formed InGaN quantum dots for exciton localization in the purple laser diode emitting at $420 \mathrm{~nm}$, Appl. Phys. Lett. 70 (1997) 981.

[56] Y. Narukawa, Y. Kawakami, Sz. Fujita, Sg. Fujita, and S. Nakamura, Recombination dynamics of localized excitons in In0.20Ga0.80N-In0.05Ga0.95N multiple quantum wells Phys. Rev. B 55 (1997) R1938-R1941. 